\title{
Motivating and retaining local government workers: what does it take?
}

\author{
Robyn Morris $^{\mathrm{a}}$ \\ ${ }^{\text {a }}$ School of Law and Justice, Faculty of Business and Law, Edith Cowan \\ University, r.morris@ecu.edu.au
}

\begin{abstract}
The capacity of local government to recruit appropriately qualified staff, motivate employees to give their best effort, and keep voluntary staff turnover low directly affects council operational performance. In addition, high staff turnover increases staffing costs and results in a loss of skill and know-how to the organisation. Yet for many years now local government managers have expressed concerns about their capacity to find, motivate and retain suitably qualified staff. This ability is critical to public service success and reform, thus needs to be a high priority if local government is to meet the challenges of the $21^{\text {st }}$ century. This paper presents the findings of a rigorous empirical study that formed part of a larger research program. Data was collected from 500 employees in 12 metropolitan, regional/ rural Western Australian local governments. It examines what factors affect three critical workplace outcomes - job satisfaction, worker willingness to exert discretionary effort, and turnover intentions - all of which have important implications for workforce planning and development. The findings provide useful and usable knowledge for improving our understanding of employee motivation and retention in the public service. From a practical perspective it can enhance public sector manager capacity to maximise the potential of human resources recruited by offering a framework of mechanisms through which managers can influence employee discretionary work effort and retention. By creating an attractive place of employment local governments can better retain staff and build a greater pool of talent from which to choose.
\end{abstract}

\section{Introduction}

This paper draws on the findings of a larger program of research that investigated the relationship between several key work outcomes, monetary reward, and non-monetary working conditions called 'perks' and 'irks' (Douglas \& Shepherd 2000). Perks are the positive non-monetary work environment factors and irks are the negative non-monetary work environment factors associated with a job and organisation (Morris \& Douglas 2004). This paper focuses on the impact of monetary and non-monetary factors on three 
work outcomes - job satisfaction, discretionary work effort (DWE) and turnover intentions.

Put simply, job satisfaction is how much one likes his/her job (Spector 1985); the feelings employees have towards aspects of their work situation (Smith, Kendall \& Hulin 1969). Turnover intentions are one's desire or willingness to leave an organisation (Bouckenhooghe 2013). Broadly, DWE is voluntarily 'going the extra mile' (Yankelovich \& Immerwahr 1983; Dubinsky \& Skinner 2002). No universal definition of DWE exists so for this research it was defined as the voluntary contribution of extra effort to work activities beyond what is minimally required, expected or enforceable by the organisation in a manner that is consistent with its goals and is intended to have a beneficial impact on its overall effectiveness (Morris 2009).

These work outcomes are important. Job satisfaction is an indicator of employee wellbeing (Noblet et al. 2005) and leads to action tendencies such as staying at an organisation or seeking employment elsewhere (Spector 1997). Evidence suggests that this attitude is related to employee turnover (e.g. Carsten \& Spector 1987; Tett \& Meyer 1993; Spector 1997) and exerting extra effort (e.g William \& Anderson 1991). Turnover intentions are used as a proxy for actual voluntary turnover (Cotton \& Tuttle 1986; Lambert 2006; Mitchell et al. 2000) as intent correlates with actual behaviour (e.g. Steele \& Ovalle 1984). Staff turnover affects an organisation's staffing costs and retention of skills and knowhow. Furthermore, it affects employee willingness to contribute meaningfully to an organisation (Matz et al. 2012). Thus, turnover intent can affect organisational performance and effectiveness as can DWE (e.g. Organ, Podsakoff \& McKenzie 2006), as effort is a key element in employee performance.

\section{The research framework}

This research was embedded in the economics utility theory (Alchian \& Demsetz 1972; Hicks 1963) and organisational behaviour expectancy theory (Vroom 1964) cognitive choice frameworks. These models pose that motivation to engage in a chosen behaviour results from rational choice based on subjective assessments of expected outcomes associated with that behaviour and the perceived attractiveness of the outcomes (Steel \& Konig 2006). Under the utility model, a person responds to environmental stimuli in a way that provides the greatest overall satisfaction. Under the expectancy model, a person's values and beliefs determine behaviour as governed by expectancies about resulting outcomes and the value placed on them. 


\section{Work outcomes and the non-monetary work environment}

Using a combination of literature, individual interviews, focus groups and a survey, five perks (challenging work, team-oriented leadership, co-worker support, flexible work arrangements, and recognition for good performance) and three irks (autocratic leader behaviour, co-worker shirking, and power-orientation) believed to affect the work outcomes of interest were identified,.

Challenging work is work that provides personal challenge and opportunities to tackle new tasks, use and extend one's skills and learn new things. It promotes employee growth and skill development by providing challenge, meaning, autonomy, and variety (Hackman \& Oldham 1976; Parker \& Wall 1998; Skinner 2000) and is intrinsically satisfying, allowing employees to attain higher order needs like self-actualisation (Herzberg 2003; Maslow 1954; McClelland 1961). This perk should increase DWE (Amabile 1997; Bateman \& Crant 1999; Chiaburu \& Baker 2006; Goldsmith, Veum \& Darity 2000; Ohly, Sonnentag \& Plunkte 2006) and job satisfaction, and reduce turnover intentions.

Team-oriented leadership is leader behaviour that encourages and builds team play, and demonstrates support and concern for all team members. Amabile and colleagues (2004) called this 'positive leader behaviours', which encompassed supporting work group members, valuing individual contributions, providing a good work model, giving positive and timely feedback, and openness to team member ideas (Amabile 1997). Emphasising team play promotes feelings of fairness, cooperation, group identity, responsibility towards attaining group goals, mutual respect, confidence and trust in the leader. This evokes a perception that the leader is concerned with their personal welfare giving employees a sense of belonging. This builds high quality leader-employee relationships (Organ, Podsakoff \& McKenzie 2006). According to social exchange theory (Blau 1964), this encourages employees to reciprocate through extra effort and organisational commitment, reducing the desire to leave.

Co-worker support is how much work group members value member contributions and show concern for group member well-being through acts of constructive support and feedback. Co-worker behaviours can influence how employees perceive and experience the work environment (Organ et al. 2006). A supportive team environment builds perceptions of being valued and cared about, fostering feelings of acceptance and belonging. This builds group commitment to attaining group goals and encourages reciprocation (Bishop, Scott \& Burroughs 2000; Organ et al. 2006). Strong co-worker support should promote job satisfaction, lower turnover intentions and motivate employee DWE (e.g. Amabile et al. 1996; Parker et al. 2006; Bateman \& Organ 1983). 
Flexible work arrangements (Bolino \& Turnley 2003; Shinn 2004) and recognition for good performance are key aspects of organisational support. Flexible work arrangements refer to an organisation's preparedness to be flexible in how it adheres to rules and procedures on how employees meet job requirements. This signals its willingness to provide employees with the help needed to perform their job well and indicates the value placed on their contributions and well-being (Eisenberger et al. 1986; Rhoades \& Eisenberger 2002). Few studies have specifically addressed flexible work arrangements as an element of organisational support. Workaholic research, however, provides some evidence that work-life balance covaries with high effort, especially amongst workaholics who enjoy their work (Burke 2000; Burke 2001a; Burke 2001b), thus, this perk should raise job satisfaction and DWE, and lower turnover intentions.

Recognition for good performance is how much an organisation recognises and rewards high effort and good performance. Employees need to believe that effort and good performance lead to valued outcomes. Machlowitz (1980) argued that recognition and reward for effort and good work provides 'psychic income' (satisfaction) that motivates extraordinarily high effort. By recognising and rewarding effort and good performance, employee performance-reward expectancies, an important work motivation element (Vroom 1964), are strengthened. This communicates to employees how much the organisation values their contributions. Strong support exists for recognition of good performance increasing job satisfaction and DWE (Choi 2007; Van Dyne, Graham \& Dienesch 1994; Peiperl \& Jones 2001; Akerloff \& Yellen 1990; Amabile 1997). Increased expectancy of valued outcomes from high effort and good performance should also decrease turnover intentions.

Autocratic leader behaviour refers to manager behaviours that negatively affect employees' psychological and/or emotional state, or make it difficult for them to perform their job. This is similar to non-contingent punishment and abusive supervision. Noncontingent punishment involves a manager administering punishment for reasons other than poor effort or performance (Organ et al. 2006). Abusive supervision is a leader's sustained display of hostile verbal and non-verbal behaviours (Tepper 2000). Theoretically, negative leader behaviour breaches the leader-employee psychological contract and so undermines employee trust and loyalty (Frey 1993; Tomer 1981). Abusive leader behaviour that publicly humiliates an employee can lower self-esteem, create dissatisfaction and decrease DWE. Social exchange and reciprocity theory plausibly suggest that negative leader behaviour is considered unfair and creates feelings of mistrust and dislike for the leader (Organ et al. 2006). Negative or hostile leader behaviours are reciprocated with negative employee responses (negative reciprocity) such as reduced effort or leaving the organisation (Gould-Williams 2007; Uhl-Bien \& 
Maslyn 2003). Most leader behaviour theories focus on positive rather than negative leader behaviours (Amabile et al. 2004). Empirical research on negative leader behaviours is limited, but Amabile et al. (2004) suggested that these behaviours may be more potent than positive leader behaviours in affecting certain discretionary work behaviours. It is theoretically feasible that negative leader behaviours will lower job satisfaction and DWE, and increase turnover intentions.

Co-worker shirking involves co-workers not giving 100\% effort or not carrying their weight on a group task. It includes co-workers neglecting their own work through frequent absence, lateness, breaks or poor quality work. Research on co-worker shirking is relatively recent. According to equity and justice theories, if employees perceive their co-workers are contributing less effort than other work group members but receive similar rewards, this creates feelings of injustice, lowers satisfaction and negatively affects work motivation (the 'sucker effect'). Employees see the work group as less cohesive and become less willing to help other work group members, especially shirkers. Theoretically, co-worker shirking will plausibly generate employee dissatisfaction and lower the DWE of affected employees since lowering one's effort re-establishes the balance between the rewards received and the effort contributed relative to shirking coworkers. Nonetheless, co-worker shirking research has found evidence of both reduced effort - a 'sucker effect' (Mulvey \& Klein 1998) - and increased effort - a 'social compensation effect' (Williams \& Karau 1991) - although evidence of a 'sucker effect' seems more extensive. Williams and Karau (1991) also conceded that either the 'sucker effect' or the 'exit option' (voluntary turnover) is likely to dominate over time. Thus, this irk should reduce job satisfaction and DWE, and riase turnover intentions.

Power-orientation is how much employees perceive their organisation is characterised by destructive internal competition, political problems and a fear of challenging people in positions of authority or influence. This involves shifting responsibilities and blame onto others, playing political power games, criticising new ideas and poor communication. Power-orientation can impede employee engagement (Amabile et al. 1996). Political problems, negative criticism and severe sanctions on failure and non-conformity increase the perceived risks of engaging in non-conforming behaviours and lower the perceived benefits. Within a social exchange and reciprocity framework, a high power-orientation fails to foster personal responsibility, loyalty, organisational commitment and satisfaction, instead creating feelings of 'negative reciprocity' (Gould-Williams 2007; Uhl-Bien \& Maslyn 2003). Thus, theoretically, this irk should generate dissatisfaction, increase the desire to leave and lower DWE (Adler \& Borys 1996; Cropanzano et al. 1997; Ferris \& Kacmar 1992). Limited research on the effects of power-orientation on work outcomes was found (Amabile et al. 1996; 
Cropanzano et al. 1997; Randall et al. 1999). The findings, however, support Adler and Borys's (1996) contention that when employees perceive an organisation as coercive, they become alienated and respond negatively.

\section{Work outcomes and monetary reward}

The role of money as a motivator of work outcomes has long been a point of contention, especially between economists and organisational psychologists. While these researchers recognise that both monetary and non-monetary work environment factors play a part, labour economists typically emphasise money while organisational behaviour researchers emphasise non-monetary factors (perks and irks). This research tested these opposing assertions.

The positive effect of monetary reward on job satisfaction is quite well established. Pay and benefits is a common component in measures of job satisfaction (e.g. Chalykoff and Kochan 1989). Thus, monetary reward should increase job satisfaction. Also, local government managers often contend that the sector cannot effectively compete against the private sector for talented staff because it cannot offer sufficiently competitive salaries (e.g. Morris 2009; Morris, Callaghan \& Walker 2010). Thus, turnover intentions should be negatively related to monetary reward.

From the preceding discussion it is anticipated that:

1. Challenging work, team-oriented leadership, co-worker support, support for flexible working arrangements and recognition for good performance are perks that will increase job satisfaction and DWE, and reduce turnover intentions

2. Autocratic leader behaviour, co-worker shirking and power orientation are irks that will lower job satisfaction and DWE, and increase turnover intentions

3. Monetary reward will be positively associated with job satisfaction and DWE, and inversely related to turnover intentions.

Figure 1 summarises these expected relationships.

\section{Method}

\section{Research context}

Local government is an important sector in Australia. It provides essential local services and makes a significant contribution to the economy (Aulich 1999; Commonwealth of Australia 2005; Commonwealth of Australia 2006), accounting for about 2.3\% of GDP (ABS 2007; Commonwealth of Australia 2006). Despite its relative size and importance, it has attracted much less research attention on employee work 
outcomes than the private sector, especially in relation to how work environment factors affect work outcomes like DWE and employee well-being (Brown \& Leigh 1996; Chiaburu \& Baker 2006; Drago 1991; Morrison \& Phelps 1999; Stamper \& Van Dyne 2001). Although a small body of public sector employee work outcome research is emerging (Albrecht 2005; Alotaibi 2001; Coyle-Shapiro \& Kessler 2000; Coyle-Shapiro \& Kessler 2002; Frank \& Lewis 2004; Noblet et al. 2006; Tepper et al. 2004; Turnipseed \& Murkison 2000), theory development, systematic empirical research and improving our understanding public sector work motivation still need greater attention (Perry \& Wise 1990; Rainey \& Steinbauer 1999; Wright 2001).

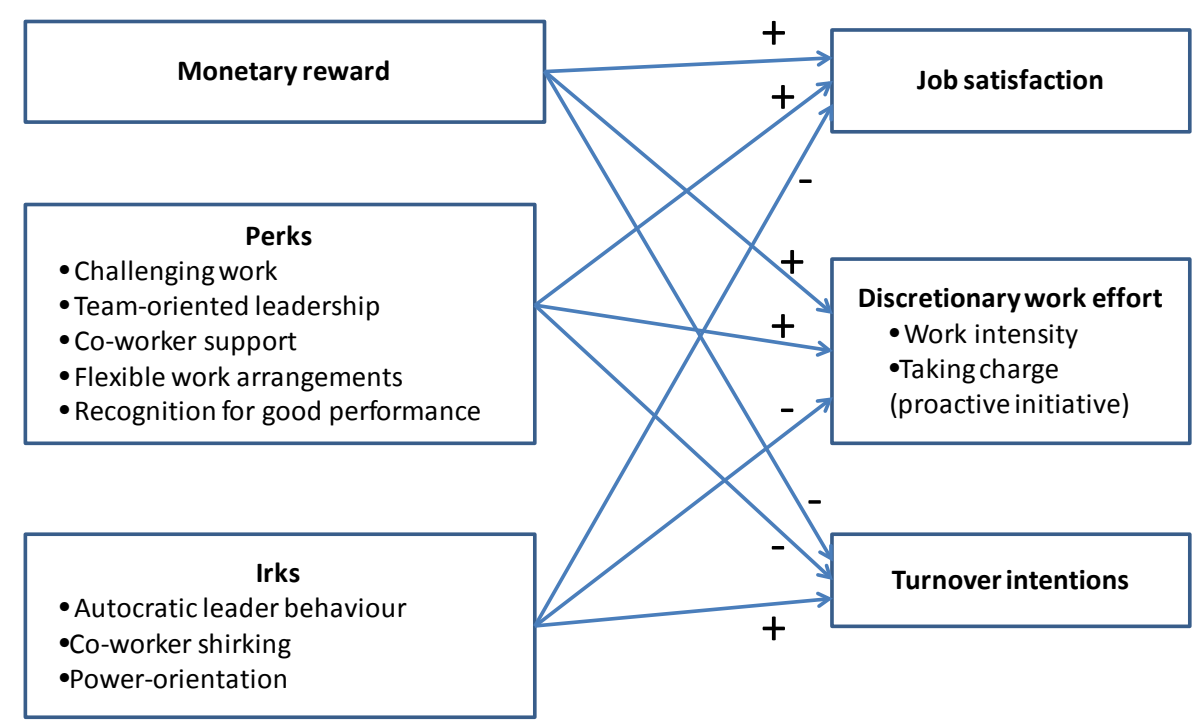

Fig. 1. Research model

In Australia, a national public sector reform agenda aimed at making local government more businesslike, performance oriented and focussed on high quality service delivery (Aulich 1999; Commonwealth of Australia 2006; Worthington \& Dollery 2002) has exposed this sector to an environment of dramatic and continuous change (Worthington \& Dollery 2002). Within this reform process, local government managers were encouraged to adopt a new public management philosophy to improve the efficiency and effectiveness of public sector management (Bradley \& Parker 2001; Teo, Ahmad \& Rodwell 2003). This reform agenda gave local government greater authority, autonomy and flexibility while simultaneously exposing it to greater uncertainty, competition, turbulence and financial and sustainability challenges (Aulich 1999; Commonwealth of Australia 2001; Commonwealth of Australia 2006; Craven 2006; Worthington \& Dollery 2002). Fiscal pressures intensified with declining revenue transfers and cost shifting by Federal and State governments. Heightened community 
expectations added to these pressures. Unprecedented economic growth in some states exacerbated an already acute national labour and skills shortage creating critical shortages in technical and professional staff that are central to local government roles. Wages were driven up, rendering local government even less competitive due to regulatory and financial constraints. Poaching behaviour favoured councils better equipped to reward and support their employees (Craven 2006). This environment created major challenges for local governments (Craven 2006). These pressures have eased in recent years but local government managers still express concerns about attracting and retaining staff (Morris et al. 2010; Morris 2011).

To improve its efficiency and effectiveness, and to meet its future challenges, local government managers need to find ways to create a workplace environment that is attractive and creates a passion for ensuring efficient and effective service delivery to communities. This means identifying key motivators of work outcomes like employee well-being, DWE and staff retention is critical.

This research was conducted in the WA local government sector. Local government is WA's third largest employer with employment growing 27\% from 2000-2005 (Commonwealth of Australia 2006; Craven 2006). At the time of this study, WA local government offered an interesting context for investigation as it was under pressure on all fronts - structural reform, intensifying fiscal pressures, unprecedented economic growth, tight labour markets and heightened community expectations.

\section{Sample participants}

The target participants for this study were all non-CEO employees from three metropolitan and nine regional/rural councils (about 9\% of all WA councils). This sample provided diversity rather than representativeness across some key criteria location, size, remoteness, local government classification and reputation within the industry - and captured a wide variety of employees including supervisory and nonsupervisory staff, full-time and part-time employees, and professional, clerical/administrative and blue-collar workers, as well as a broad range of occupational groups. Collectively these councils employed about 2,200 staff.

Data was collected from 500 employees. Individual council response rates ranged from $10 \%$ to $71 \%$ (median of $29 \%$ ). About two-thirds of participants worked in rural/regional councils and nearly 60\% were male. The median age group was 40-49 years and $61 \%$ of respondents were aged $40+$ years. Most participants (84\%) worked full-time and $60 \%$ had worked in their organisation for five years or less. About $40 \%$ were in a supervisory role and almost one-quarter (24\%) were 'outside' staff. 


\section{Procedure}

The data was collected using a self-administered structured questionnaire distributed via either internal mail or by the researcher on a site visit. A cover letter outlined the study aims, benefits of participation, assurances of confidentiality, and highlighted the support of two peak industry bodies. Two reminders were sent via email or council newsletter after two and four weeks. Anonymously completed questionnaires were returned by reply-paid mail or directly during site visits.

\section{Measures}

The questionnaire consisted of self-report scales designed to measure key variables that included job satisfaction, turnover intentions and DWE as dependent variables, and monetary reward and the eight non-monetary work environment factors as predictor variables. Demographic information - gender, age, job status and tenure with the organisation - was also collected as control variables. This study used a combination of established measures and new scales developed as part of the larger research program.

Job satisfaction was measured using four items adapted from a scale developed by Chalykoff and Kochan (1989) and two new items that captured various aspects of the workplace (job, pay and benefits, management etc.) A seven-point pictorial scale from 'very dissatisfied' to 'very satisfied' was used, with higher scores reflecting higher satisfaction. The Cronbach’s alpha reliability was 0.83 .

Turnover intentions was measured using three items drawn from several sources. A seven-point scale from 'strongly disagree' to 'strongly agree' was used with higher scores representing higher turnover intentions. The Cronbach's alpha reliability was 0.92 .

Discretionary work effort is a multidimensional concept. No established scales incorporated all the DWE dimensions so a new scale was developed using several existing sub-scales including adapted versions of Brown and Leigh's (1996) work intensity and Morrison and Phelps's (1999) taking charge (proactive initiative). The final DWE scale included a four-item work intensity sub-scale and a six-item taking charge sub-scale. Participants were asked to think about their present job and to indicate how much they agreed with each statement. A seven-point scale from 'strongly disagree' to 'strongly agree' was used, with higher scores representing greater DWE. The 'work intensity' and 'taking charge' sub-scales had Cronbach's alpha reliabilities of 0.83 and 0.87 , respectively.

Monetary reward was measured using a single item; employee's total yearly income inclusive of base pay, overtime pay, any bonuses or allowances, any paid time off and any other direct payments, but excluding indirect benefits forming part of a 'package' 
such as a company car, company superannuation contributions, and conference allowances. Ten response categories were provided and subsequently reduced to right categories, from under $\$ 30,000$ to $\$ 100,000+$, with $\$ 10,000$ increments in between.

Non-monetary work environment factors were assessed using a 41-item scale designed to measure the salient perks and irks: challenging work (five items), teamoriented leadership (seven items), co-worker support (six items), flexible work arrangements (three items), recognition for good work (four items), autocratic leader behaviour (five items), co-worker shirking (seven items), and power-orientation (four items). Participants indicated how accurately each item described their current work environment using a seven-point scale ranging from 'very inaccurate' to 'very accurate'. These sub-scales had Cronbach's alpha reliabilities between 0.74 and 0.90 .

Demographic Measures - gender, age, work status and organisational tenure - were all measured as absolute variables. Gender was binary, with $0=$ male and $1=$ female. Age was measured in 10 year blocks from under 20 years to 60+ years. Work status was binary, with $0=$ full-time and $1=$ part-time/casual. And organisational tenure had six categories - under 1 year, 1-2 years, 3-5 years, 6-10 years, 11-15 years and 16+ years later combined into five year blocks for analysis.

\section{Data analysis}

All scale measures were subjected to confirmatory factor analysis to assess their measurement quality prior to further analysis. Some scale re-specification was necessary to ensure an adequate measurement model fit while ensuring content validity was maintained. Scale scores were calculated by averaging the items in each scale.

To answer the research question 'what work environment factors affect job satisfaction, DWE and turnover intentions?', correlation, regression and effect size analyses were conducted. This involved four stages:

1. An inter-correlation matrix generated for all variables

2. Separate pairwise hierarchical regressions with each work outcome regressed on each individual monetary and non-monetary work environment factor after controlling for the demographics

3. Effect size correlations assessed using Cohen's cut-off criteria: small $(0.1<\mathrm{r}$ $\leq 0.243)$; medium $(0.243<\mathrm{r} \leq 0.371)$; and large $(\mathrm{r}>0.371)$

4. Hierarchical multiple regressions with each work outcome regressed on the demographic variables in step one, then all work environment factors entered in step two. Predictors without a significant effect size were excluded.

Statistical significance was assessed at $1 \%$ to allow for possible error from repeated analyses. 


\section{Results}

Table 1 provides an overview of the key results (see the Appendix for more detailed results). Overall, there were significant correlations between most work outcomes (dependent variables) and the work environment factors (predictor variables), and some participant demographics (control variables). All dependent and predictor variables displayed reasonable variability and their inter-correlations were all in their predicted directions.

\section{Association between work outcomes}

All the work outcomes displayed significant inter-correlations. These ranged from a high of -0.64 (strong) between job satisfaction and turnover intentions to a low of -0.20 (weak) between turnover intentions and taking charge. Job satisfaction had the strongest association with the other work outcomes (average $r=0.41$ ) while the taking charge DWE measure had the weakest (average $r=0.27$ ). The average correlation across all work outcomes was 0.35 (moderate).

\section{Association between the work environment factors}

All the non-monetary work environment factors also displayed significant intercorrelations. The inter-correlations between the perks ranged from a high of 0.61 between challenging work and team-oriented leadership to a low of 0.29 between coworker support and flexible work arrangements. The average correlation across all perks was 0.44 . In contrast, the inter-correlations between the irks were only moderate and much less divergent. They ranged from 0.30 to 0.34 . The inter-correlations between the perks and irks were moderate to strong. They ranged from a high of -0.67 between teamoriented leadership and autocratic leader behaviour to a low of -0.17 between co-worker shirking and flexible work arrangements. Monetary reward had weak to non-significant correlations with the non-monetary factors. Its average correlation with all perks was 0.12 and with all irks was 0.08 .

\section{Job satisfaction and the work environment factors}

As anticipated, all the perks were positively correlated with job satisfaction while all the irks had negative correlations. Job satisfaction was strongly $(r>0.5)$ to very strongly $(r>$ $0.7)$ correlated with perks, moderately $(r>0.3)$ to strongly $(r>0.5)$ associated with irks, and very weakly related to monetary reward. The strongest significant correlation was with team-oriented leadership $(r=0.77)$, closely followed by challenging work $(r=$ $0.66)$, recognition for good performance $(r=0.66)$ and autocratic leader behaviour $(r=-$ 
0.64). The weakest association was with monetary reward $(r=0.13)$. Overall job satisfaction was more strongly correlated with the perks than with irks and monetary reward.

Although these inter-correlation suggested that job satisfaction is significantly associated with all the work environment factors, this does not provide full insight to how much each factor impacts this work outcome since employee demographics can have confounding effects. The two-step pairwise hierarchical regressions firstly clarified the predictive capacity of each factor after controlling for participant demographics (see column 1 in Table 1). Effect size correlations were also determined to assess the relative size of the effect of each predictor on job satisfaction (see column 2 in Table 1). Further, to answer the question 'what unique contribution does each factor make to job satisfaction when all the work environment factors are considered together', the two-step hierarchical multiple regression results were examined.

Having controlled for the participant demographics, the pairwise regression results virtually mirrored the correlation results. Collectively, the control variables accounted for about $5 \%$ of the variation in job satisfaction $(\mathrm{p}<0.001)$. Individually, each work environment factor explained between 5\% and 57\% extra variation in job satisfaction and was statistically significant. The largest individual predictors of job satisfaction were team-oriented leadership (57\%), challenging work (41\%), recognition for good performance (40\%) and autocratic leader behaviour (38\%), although every perk and irk had large effect sizes. Contrary to some employer beliefs, monetary reward only had a small effect size and the smallest predictive capacity explaining only $5-7 \%$ of job satisfaction.

When all work environment factors were entered together, flexible work arrangements, power-orientation and monetary reward were no longer significant predictors of job satisfaction, indicating that even though these factors are significantly related to this work outcome the significant work environment factors subsume their effect so they make no unique contribution to job satisfaction above these factors (see column 3 in Table 1).

Team-oriented leadership made the largest unique contribution to job satisfaction, followed by recognition for good performance, challenging work and autocratic leader behaviour, all being highly significant predictors $(\mathrm{p}<0.001)$. Although co-worker shirking and co-worker support also made unique contributions to job satisfaction, their magnitude and their significance were considerably smaller. Collectively, these factors explained $71 \%$ of job satisfaction. 
Tab. 1. Overview of the findings

\begin{tabular}{|c|c|c|c|c|c|c|c|c|c|c|c|c|}
\hline \multirow[b]{5}{*}{ Predictor variables } & \multicolumn{12}{|c|}{ Work outcomes - dependent variables (DV) } \\
\hline & \multirow{2}{*}{\multicolumn{3}{|c|}{ Job satisfaction }} & \multirow{2}{*}{\multicolumn{3}{|c|}{ Turnover intentions }} & \multicolumn{6}{|c|}{ Discretionary work effort } \\
\hline & & & & & & & \multicolumn{3}{|c|}{ Intensity } & \multicolumn{3}{|c|}{ Taking charge } \\
\hline & (1) & $(2)$ & (3) & (4) & (5) & (6) & (7) & (8) & (9) & (10) & (11) & (12) \\
\hline & $\begin{array}{l}\text { PR \% DV } \\
\text { variation } \\
\text { explained }\end{array}$ & $\begin{array}{c}\text { Size of } \\
\text { effect size }\end{array}$ & $\begin{array}{l}\text { MR unique } \\
\text { contribution } \\
\text { p-value }\end{array}$ & $\begin{array}{l}\mathrm{PR} \% \mathrm{DV} \\
\text { variation } \\
\text { explained }\end{array}$ & $\begin{array}{c}\text { Size of } \\
\text { effect size }\end{array}$ & $\begin{array}{l}\text { MR unique } \\
\text { contribution } \\
\text { p-value }\end{array}$ & $\begin{array}{l}\mathrm{PR} \% \mathrm{DV} \\
\text { variation } \\
\text { explained }\end{array}$ & $\begin{array}{l}\text { Size of } \\
\text { effect size }\end{array}$ & $\begin{array}{l}\text { MR unique } \\
\text { contribution } \\
\text { p-value }\end{array}$ & $\begin{array}{l}\text { PR \% DV } \\
\text { variation } \\
\text { explained }\end{array}$ & $\begin{array}{c}\text { Size of } \\
\text { effect size }\end{array}$ & $\begin{array}{l}\text { MR unique } \\
\text { contribution } p- \\
\text { value }\end{array}$ \\
\hline $\begin{array}{l}\text { Control variables - participant } \\
\text { demographics }\end{array}$ & $5 \% \ddagger$ & & & $5 \% \ddagger$ & & & $9 \% \ddagger$ & & & $2 \%$ n.s. & & \\
\hline \multicolumn{13}{|c|}{ Perks - non-monetary factors } \\
\hline Challenging work & $41 \% \ddagger$ & L & $\ddagger$ & $21 \% \ddagger$ & L & $\ddagger$ & $13 \% \ddagger$ & L & $\ddagger$ & $10 \% \ddagger$ & M & $\ddagger$ \\
\hline Team-oriented leadership & $57 \% \ddagger$ & L & $\ddagger$ & $21 \% \ddagger$ & L & n.s. & $7 \% \ddagger$ & M & n.s. & $5 \% \ddagger$ & S & n.s. \\
\hline Co-worker support & $20 \% \ddagger$ & L & $*$ & $5 \% \ddagger$ & M & n.s. & $8 \% \ddagger$ & M & $\ddagger$ & $6 \% \ddagger$ & M & $\ddagger$ \\
\hline Flexible work arrangements & $20 \% \ddagger$ & L & n.s. & $8 \% \ddagger$ & M & n.s. & $4 \% \ddagger$ & $\mathrm{S}$ & n.s. & $8 \% \ddagger$ & M & $\ddagger$ \\
\hline $\begin{array}{l}\text { Recognition for good } \\
\text { performance }\end{array}$ & $40 \% \ddagger$ & L & $\ddagger$ & $22 \% \ddagger$ & L & $\ddagger$ & $3 \% \ddagger$ & s & $t^{1}$ & $3 \% \ddagger$ & s & n.s. \\
\hline \multicolumn{13}{|c|}{ Irks - non-monetary factors } \\
\hline Autocratic leader behaviour & $38 \% \ddagger$ & L & $\ddagger$ & $17 \% \ddagger$ & $\mathrm{L}$ & + & $3 \% \ddagger$ & $\mathrm{S}$ & n.s. & $2 \% *$ & $\mathrm{~s}$ & n.s. \\
\hline Co-worker shirking & $15 \% \ddagger$ & L & $\dagger$ & $5 \% \ddagger$ & M & n.s. & $1 \% \bar{\uparrow}$ & s & $\bar{\uparrow}$ & $1 \% \bar{\uparrow}$ & $\mathrm{s}$ & n.s. \\
\hline Power-orientation & $15 \% \ddagger$ & L & n.s. & $11 \% \ddagger$ & $\mathrm{M}$ & n.s. & $3 \% \ddagger$ & $\mathrm{s}$ & $*$ & $0 \%$ n.s. & n.s. & \\
\hline \multicolumn{13}{|c|}{ Monetary factors } \\
\hline $\begin{array}{l}\text { Monetary reward } \\
\text { (approx. Interval/cat. scale) }\end{array}$ & $5 / 7 \% \ddagger$ & S & n.s. & 0/2\% n.s. & n.s. & & 0/1\% n.s. & n.s. & & $3 / 6 \% \ddagger$ & S & $\bar{\uparrow}$ \\
\hline $\begin{array}{l}\text { MR Step } \mathbf{2}-\Delta \mathbf{R}^{\mathbf{2}} \\
\text { (Total variation in DV } \\
\text { explained by all predictors) }\end{array}$ & & & 0.71 & & & 0.32 & & & 0.19 & & & 0.17 \\
\hline
\end{tabular}

$\mathrm{PR}=$ pairwise hierarchical regression results $\left(\Delta \mathrm{R}^{2}\right)$; $\mathrm{MR}=$ multiple hierarchical regression results

$\mathrm{S}=$ small effect size; $\mathrm{M}=$ medium effect size; $\mathrm{L}=$ large effect size

$\overline{\mathrm{T}} \mathrm{p}<0.05 ; * \mathrm{p}<0.01 ; \dagger \mathrm{p}<0.005 ; \ddagger \mathrm{p}<0.001 ; \mathrm{n} . \mathrm{s} .=$ not significant $(\mathrm{n}=500)$

${ }^{1}$ Unexpected reversal of sign in the multiple regression - possible confounding effect. 


\section{Turnover intentions and the work environment factors}

As predicted, all the perks were inversely related to turnover intentions while all the irks had significant positive correlations. This work outcome was moderately correlated with all perks and irks $(\mathrm{p}<0.001)$ but was not significantly associated with monetary reward $(\mathrm{p}>0.05)$. The strongest significant correlation was with recognition for good performance $(r=-0.50)$ followed by teamoriented leadership and challenging work (both $r=-0.48)$, and autocratic leader behaviour $(r=0.44)$. The weakest association was with co-worker support $(r=-0.27)$ and co-worker shirking $(r=0.27)$. Like job satisfaction, turnover intentions were more strongly correlated with perks than with irks.

When controlling for participant demographics, the pairwise regression results again largely mirrored the inter-correlation results. The control variables accounted for about $5 \%$ of turnover intentions $(\mathrm{p}<0.001)$. Individually, each non-monetary work environment factor then explained between $5 \%$ and $22 \%(\mathrm{p}<0.001)$ extra variation in turnover intentions (see column 4 in Table 1). Three perks and one irk predicted similar levels of turnover intentions - recognition for good performance (22\%), team-oriented leadership and challenging work (each 21\%), and autocratic leader behaviour (17\%) and had large effect sizes (see column 5 in Table 1). These were followed by powerorientation (11\%) which had a medium effect size. Again, contrary to the beliefs of many local government managers, monetary reward had a very small effect size and accounted for only $0-2 \%$ of turnover intentions which was not statistically significant.

When all work environment factors were entered together, only two perks and one irk made a unique contribution to explaining turnover intentions, subsuming the effects of the other predictors (see column 6 in Table 1). Recognition for good performance and challenging work made the largest unique contributions $(p<0.001)$ followed by autocratic leader behaviour $(p<0.005)$. Together, these factors explained about $32 \%$ of turnover intentions.

\section{Discretionary work effort and the work environment factors}

All the perks were positively correlated with both DWE measures. However, while all the irks had significant negative correlations with work intensity, only autocratic leader behaviour was significantly correlated with taking charge $(\mathrm{p}<0.005)$, and co-worker shirking was marginally correlated $(\mathrm{p}<0.05)$. In contrast, monetary reward was significantly associated with the taking charge DWE measure $(\mathrm{p}<0.001)$ but not with the intensity DWE measure $(\mathrm{p}>0.05)$. Work intensity was most strongly related to challenging work $(r=0.38)$ and most weakly related to co-worker shirking ( $\mathrm{r}$ $=-0.15)$. Similarly, taking charge was most strongly related to challenging work $(r=0.33)$ and most weakly correlated with autocratic leader behaviour $(r=-0.13)$.

Overall, the predictive capacity of the individual work environment factors in explaining the two DWE measures was smaller than for both job satisfaction and turnover intentions. For work intensity, only challenging work had a large effect size accounting for $13 \%$ of this component of DWE. Team- 
oriented leadership and co-worker support had medium effect sizes, each explaining 7-8\% of work intensity. All the other perks and irks had small effect sizes and accounted for 1-4\% of variation, although co-worker shirking was only marginally significant $(\mathrm{p}<0.05)$. The unique effects of challenging work and co-worker support on work intensity was apparent in the multiple regression as these were both highly significant $(\mathrm{p}<0.001)$ and subsumed the effects of all other factors except recognition for good performance which, although significant, had an unexpected reversal of relationship which is difficult to explain and may simply be a confounding effect. For taking charge, the individual work environment factors had only small to medium effect sizes explaining $1-10 \%$ of the variation in taking charge behaviour. Co-worker shirking had a marginal negative effect and power-orientation had no significant effect. Together these predictors explained 19\% of work intensity and $17 \%$ of taking charge behaviour.

\section{Discussion}

These findings indicate that perks and irks have a larger effect than monetary reward on job satisfaction, DWE and turnover intentions. Further, they show that while all these work environment factors affect at least some work outcomes, the combination of factors with the greatest impact differ across work outcomes. Table 2 summarises the key factors contributing uniquely to the work outcomes examined.

Tab. 2. Summary of the unique factors affecting key work outcomes

\begin{tabular}{lcccc} 
Work environment factors & $\begin{array}{c}\text { Job } \\
\text { satisfaction }\end{array}$ & $\begin{array}{c}\text { Turnover } \\
\text { intentions }\end{array}$ & $\begin{array}{c}\text { Work } \\
\text { intensity }\end{array}$ & $\begin{array}{c}\text { Taking } \\
\text { charge }\end{array}$ \\
\hline Challenging work & $\uparrow$ & $\downarrow$ & $\uparrow$ & $\uparrow$ \\
\hline Team-oriented leadership & $\uparrow$ & & $\uparrow$ & $\uparrow$ \\
\hline Co-worker support & $\uparrow$ & & & $\uparrow$ \\
\hline Flexible work arrangements & & $\uparrow$ & & \\
\hline Recognition for good performance & $\uparrow$ & & & \\
\hline Autocratic leader behaviour & $\downarrow$ & & & \\
\hline Co-worker shirking & $\downarrow$ & & & \\
\hline Power-orientation & & & & \\
\hline Monetary reward & & & & \\
\hline
\end{tabular}

To create a highly satisfying workplace local government needs to promote a management style that is highly supportive and team-orientated, design jobs that are challenging and interesting, recognise hard working and well performing employees, and promote a culture in which teamwork is a premium. It needs to minimise situations in which managers adopt an overly autocratic approach to 
how they manage staff, and take action to ensure all employees carry their weight. Due to the strong inverse association between job satisfaction and turnover intentions, this type of workplace should also help with retaining staff. Key factors in minimising voluntary turnover are ensuring that work is designed to be challenging and interesting, and recognising hard working and well performing employees. Autocratic leader behaviour is a key motivator for employees leaving organisations. Finally, to induce greater discretionary work effort in terms of encouraging staff to work harder and to take the initiative to find better ways of doing their job to improve service delivery, local government needs to: focus on designing jobs so that they are challenging and interesting; build teamwork amongst work groups; support flexible work arrangements; and provide a financial incentive to people who take the initiative to make improvements in their job, work unit and/or the organisation. It can be seen that job design is central to all of the work outcomes, but combined with the other key factors can potentially produce a more productive and effective local government workplace.

\section{Conclusions}

This paper examined the role of non-monetary work environment factors (perks and irks) and monetary reward as determinants of three key work outcomes: job satisfaction, turnover intentions and DWE. It extends existing knowledge by investigating the impact of several work environment factors not previously considered (most notably irks), thereby improving our understanding of how non-monetary work environment factors and monetary rewards influence different work outcomes. Also, several scholars highlighted how relatively little is known about public sector employee motivation (Frank \& Lewis 2004; Gould-Williams 2007; Perry 1997; Perry \& Wise 1990; Wright 2001) -this research makes a much needed contribution to public sector motivational research.

The findings demonstrate that to more completely understand employee work outcomes, the differential roles of the job, and interpersonal, organisational and monetary reward domains of the work environment need to be recognised. Generally, perks have a stronger and more pervasive impact than irks and monetary reward on all work outcomes investigated. Further, the importance of social and interpersonal relationships in affecting these work outcomes was clearly evident. Nonetheless, focussing on only one or a few factors provides an incomplete picture and may prevent managers from maximising their human resources potential as, individually and collectively, these factors substantively affect employee well-being as measured by job satisfaction, and most factors covary with employee turnover intentions. These findings have important implications for practicing managers and local government policymakers. 


\section{Implications for policy and practice}

Job satisfaction, turnover intentions and DWE are important factors affecting organisational performance (Gould-Williams 2007; Organ et al. 2006). These research findings can guide public sector managers on what perks and irks they need to address to enhance these key work outcomes. This knowledge, along with training in this area, will be particularly important for new managers with little or no management training and experience.

As the local government sector undergoes structural reform and faces increasing pressures to improve service delivery, it is important to better understand how different factors affect public sector employee work outcomes. This is crucial to improving organisational performance and sustainability. Further, employers and managers need to recognise the role they can play in influencing these work outcomes. Organisational leaders can shape the work environment to induce employees to engage in work behaviours that improve organisational effectiveness and performance, and reduce staff turnover. Job design and interpersonal relationships play a critical role.

Managers have a greater opportunity to influence DWE, hence worker performance, by encouraging employees to work more intensively and take the initiative to proactively challenge the status quo to bring about constructive change in one's own job, work area and the organisation (Van Dyne et al. 1995). This research highlights that to most effectively utilise their human resources (HR), managers need to address workplace perks and irks, as well as monetary rewards, to influence these key work outcomes.

By showing that different work outcomes have different predictors, these findings have important management, education and HR implications. Firstly, while many organisations traditionally rely on monetary reward and benefits to attract, retain and motivate employees, this research draws attention to the importance of 'soft perks' (Budman 1994) and 'soft' HR practices (Delery et al. 1998; Wayne, Shore \& Liden 1997) as motivators. This provides managers with a framework for better understanding how different work environment factors under their control can be adjusted to influence different work outcomes.

These findings also point to the importance of training both managers and non-supervisory employees in interpersonal relationships. Management education and HR training needs to include information on how best to design challenging and interesting jobs based on individual skills and abilities, and how best to build quality leader-employee relationships. Developing interpersonal skills in things like effective communication, team-building and conflict management, and an understanding of emotional intelligence will be important for both managers and non-supervisory staff to build an environment that fosters trust and transparency so that quality workplace relationships can develop (Ash 2000).

Finally, this research is timely for policy makers in State government, especially where significant labour shortages exist and a local government reform agenda is being progressed. Policy makers need 
to examine the capacity for public sector managers to cultivate organisational perks that can foster the formation of high quality leader-employee relationships. They also need to consider promoting and supporting local government manager training in how to cultivate perks and to address irks in their organisations. Furthermore, they need to examine how local government managers can be given greater flexibility to reward employees for good performance through a range of monetary and nonmonetary incentives. This requires a shift away from compensation practices where monetary rewards are tied to positions and industry awards and standards rather than performance.

\section{References}

Adler, P.S. \& Borys, B. 1996, 'Two types of bureaucracy: Enabling and coercive', Administrative Science Quarterly, vol. 41, no. 1, pp. 61-89.

Akerlof, G.A. \& Yellen, J.L. 1990, 'The fair wage-effort hypothesis and unemployment', The Quarterly Journal of Economics, vol. 105, no. 2, pp. 255-83.

Albrecht, S. 2005, 'Leadership climate in the public sector: Feelings matter too!', International Journal of Public Administration, vol. 28, no. 5-6, pp. 397-416.

Alchian, A.A. \& Demsetz, H. 1972, 'Production, information costs, and economic organization', American Economic Review, vol. 62, no. 5, pp. 777-95.

Alotaibi, A.G. 2001, ‘Antecedents of organizational citizenship behavior: A study of public personnel in Kuwait', Public Personnel Management, vol. 33, no. 3, 363-76.

Amabile, T.M. 1997, 'Motivating creativity in organizations: On doing what you love and loving what you do', California Management Review, vol. 40, no. 1, pp. 39-58.

Amabile, T.M., Conti, R., Coon, H., Lazenby, J. \& Herron, M. 1996, 'Assessing the work environment for creativity', Academy of Management Journal, vol. 39, no. 5, pp. 1154-84.

Amabile, T.M., Schatzel, E.A., Moneta, G.B. \& Kramer, S.J. 2004, 'Leader behaviors and the work environment for creativity: Perceived leader support', The Leadership Quarterly, vol. 15, no. 1, pp. 5-32.

Ash, C. 2000, 'Social-self-interest', Annals of Public and Cooperative Economics, vol. 71, no. 2, pp. 261-84.

Aulich, C. 1999, 'From convergence to divergence: Reforming Australian local government', Australian Journal of Public Administration, vol. 58, no. 3, pp. 12-23.

Australian Bureau of Statistics (ABS) 2007, Wage and salary earners, public sector, Australia, March 2007, cat. no. 6248.0.55.001, ABS, Canberra, viewed 11 September 2013, <http://www.abs.gov.au/AUSSTATS/abs@.nsf/productsbyCatalogue/C976CA0DFCB18A1BCA2 5707C007B02D4?OpenDocument>.

Bateman, T.S. \& Crant, J.M. 1999, 'Proactive behavior: Meaning, impact, recommendations', Business Horizons, vol. 42, no. 3, pp. 63-70. 
Bateman, T.S. \& Organ, D.W. 1983, 'Job satisfaction and the good soldier: The relationship between affect and employee "citizenship”, Academy of Management Journal, vol. 26, no. 4, pp. 587-95.

Bishop, J.W., Scott, K.D. \& Burroughs, S.M. 2000, 'Support, commitment, and employee outcomes in a team environment', Journal of Management, vol. 26, no. 6, pp. 1113-32.

Blau, G. 1964, Exchange and power in social life, Wiley, New York.

Bolino, M.C. \& Turnley, W.H. 2003, 'Going the extra mile: Cultivating and managing employee citizenship behavior', Academy of Management Executive, vol. 17, no. 3, pp. 60-71.

Boouckenhooghe, D., Raja, U. \& Butt, A.N. 2013, 'Combined Effects of Positive and Negative Affectivity and Job Satisfaction on Job Performance and Turnover Intentions', The Journal of Psychology: Interdisciplinary and Applied, vol. 147, no. 2, pp. 105-23.

Bradley, L. \& Parker, R. 2001, 'Public sector change in Australia: Are managers' ideals being realized?', Public Personnel Management, vol. 30, no. 3, pp. 349-61.

Brown, S.P. \& Leigh, T.W. 1996, 'A new look at psychological climate and its relationships to job involvement, effort, and performance’, Journal of Applied Psychology, vol. 81, no. 4, pp. 358-68.

Burke, R.J. 2000, 'Workaholism in organizations: concepts, results and future research directions', International Journal of Management Reviews, vol. 2, no. 1, pp. 1-16.

Burke, R.J. 2001a, 'Workahlism components, job satisfaction, and career prospects', Journal of Applied Social Psychology, vol. 31, no. 11, pp. 2339-56.

Burke, R.J. 2001b, 'Workaholism in organizations: the role of organizational values', Personnel Review, vol. 30, no. 6, pp. 637-45.

Carsten, J.M. \& Spector, P.E. 1987, 'Unemployment, job satisfaction and employee

turnover: A meta-analytic test of the Muchinsky model', Journal of Applied Psychology, vol. 72, no. 3, pp. 199-212.

Chalykoff, J. \& Kochan, T.A. 1989, 'Computer-aided monitoring: Its influence on employee job satisfaction and turnover', Personnel Psychology, vol. 42, no. 4, pp. 807-34.

Chiaburu, D.S. \& Baker, V.L. 2006, 'Extra-role behaviors challenging the status quo: Validity and antecedents of taking charge behaviors', Journal of Managerial Psychology, vol. 21, no. 7, pp. 620-37.

Choi, J.N. 2007, 'Change-oriented organizational citizenship behavior: effects of work environment characteristics and intervening psychological processes', Journal of Organizational Behavior, vol. 28, no. 4, pp. 467-84.

Cohen, J. 1988, Statistical power analysis for the behavioral sciences, 2nd edn, Lawrence Erlbaum Associates, Hillsdale, New Jersey.

Commonwealth Government Commission 2001, Review of the operation of the local government (financial assistance) act 1995, Panther Publishing \& Printing, Canberra.

Commonwealth of Australia 2005, Government response to the report of the house of representatives standing committee on economics, finance and public administration: Rates and taxes - A fair 
share for responsible local government, Australian Government: Department of Infrastructure and Transport, Canberra.

Commonwealth of Australia 2006, Local government national report: 2004-05 report on the operation of the local government (Financial Assistance) Act 1995, Australian Government: Department of Regional Australia, Local Government, Arts and Sport, Canberra, viewed 12 September 2013, <http://www.regional.gov.au/local/publications/reports/2004_2005/pdf/Local_report.pdf> .

Cotton, J.L. \& Tuttle, J.M. 1986, 'Employee turnover: A meta-analysis and review with implications for research', Academy of Management Review, vol. 11, no. 1, pp. 55-70.

Coyle-Shapiro, J. \& Kessler, I. 2000, 'Consequences of the psychological contract for the employment relationship: A large scale survey', Journal of Management Studies, vol. 37, no. 7, pp. 903-30.

Coyle-Shapiro, J.A.-M. \& Kessler, I. 2002, 'Contingent and non-contingent working in local government: Contrasting psychological contracts', Public Administration, vol. 80, no. 1, pp. 77101.

Craven, G. 2006, In Your Hands: Shaping the future of Local Government in Western Australia, Western Australian Local Government Association, Perth, viewed 14 June 2007, <http://www.walga.asn.au/LGReform/SystemicSustainabilityStudy/SSSPanelReport.aspx>.

Cropanzano, R., Howes, J.C., Grandey, A.A. \& Toth, P. 1997, 'The relationship of organizational politics and support to work behaviors, attitudes, and stress', Journal of Organizational Behavior, vol. 18, no. 2, pp. 159-80.

Douglas, E.J. \& Shepherd, D.A. 2000, 'Entrepreneurship as a utility maximizing response', Journal of Business Venturing, vol. 15, no. 3, pp. 231-51.

Drago, R. 1991, 'Incentives, pay and performance: a study of Australian employees', Applied Economics, vol. 23, no. 9, pp. 1433-46.

Dubinsky, A.J. \& Skinner, S.J. 2002, 'Going the extra mile: Antecedents of salespeople's discretionary effort’, Industrial Marketing Management, vol. 31, no. 7, pp. 589-98.

Eisenberger, R., Huntington, R., Hutchinson, S. \& Sowa, D. 1986, 'Perceived organizational support', Journal of Applied Psychology, vol. 71, no. 3, pp. 500-7.

Ferris, G.R. \& Kacmar, K.M. 1992, 'Perceptions of organizational politics', Journal of Management, vol. 18, no. 1, pp. 93-116.

Frank, S.A. \& Lewis, G.B. 2004, 'Government employees: Working hard or hardly working?', American Review of Public Administration, vol. 34, no. 1, pp. 36-51.

Frey, B.S. 1993, 'Does monitoring increase work effort? The rivalry with trust and loyalty', Economic Inquiry, vol. 31, no. 4, pp. 663-70.

Goldsmith, A.H., Veum, J.R. \& Darity Jr., W. 2000, 'Working hard for the money? Efficiency wages and worker effort', Journal of Economic Psychology, vol. 21, no. 4, pp. 351-85. 
Gould-Williams, J. 2007, 'HR practices, organizational climate and employee outcomes: evaluating social exchange relationships in local government', The International Journal of Human Resource Management, vol. 18, no. 9, pp. 1627-47.

Hackman, J.R. \& Oldham, G.R. 1976, 'Motivation through the design of work: Test of a theory', Organizational Behavior and Human Performance, vol. 16, no. 2, pp. 250-79.

Hamel, G. 2000, Leading the revolution, Harvard Business School Press, Massachusetts.

Herzberg, F. 2003, 'One more time: how do you motivate employees?', Harvard Business Review, vol. 46, no. 1 , pp. 36-44.

Hicks, J.R. 1963, The theory of wages, 2nd edn, Macmillan, London.

Lambert, E.G. 2006, 'I want to leave: A test of a model of turnover intent among correctional staff', Applied Psychology in Criminal Justice, vol. 2, no. 1, pp. 57-83.

Machlowitz, M. 1980, Workaholics: Living with them, working with them, Addison-Wesley, Reading, Massachusetts.

Maslow, A.H. 1954, Motivation and personality, Harper and Row, New York.

Matz, A.K., Wells, J.B., Minor, K.I. \& Angel, E. 2013, 'Predictors of turnover intention among staff in juvenile correctional facilities: The relevance of job satisfaction and organizational commitment', Youth Violence and Juvenile Justice, vol. 11, no. 2, pp. 115-31.

McClelland, D.C. 1961, The achieving society, Van-Nostrand, Princeton, New Jersey.

Mitchell, O., Mackenzie, D.L., Styve, G.J. \& Gover, A.R. 2000, 'The impact of individual, organizational, and environmental attributes on voluntary turnover among juvenile correctional staff members', Justice Quarterly, vol. 17, no. 2, pp. 333-57.

Morris, R.J. 2009, 'Employee motivation and discretionary work effort', PhD dissertation, Queensland University of Technology, Brisbane, Queensland.

Morris, R. 2011, A capacity building strategy for rural-remote and indigenous local government, Australian Centre of Excellence for Local Government, University of Technology, Sydney.

Morris, R., Callaghan, R. \& Walker, B. 2010, Rural-remote and indigenous local government: Western Australian scoping study report, Australian Centre of Excellence for Local Government, University of Technology, Sydney.

Morris, R. \& Douglas, E. 2004, Employee work effort and latent performance, paper presented to the 17th Annual Small Enterprise Association of Australia \& New Zealand Conference, Brisbane, 2629 September.

Morrison, E.W. \& Phelps, C.C. 1999, 'Taking charge at work: Extrarole efforts to initiate workplace change', Academy of Management Journal, vol. 42, no. 4, pp. 403-19.

Mulvey, P.W. \& Klein, H.J. 1998, 'The impact of perceived loafing and collective efficacy on group goal processes and group performance', Organizational Behavior and Human Decision Processes, vol. 74 , no. 1 , pp. $62-87$. 
Noblet, A.J., McWilliams, J., Teo, S.T.T. \& Rodwell, J.J. 2006, 'Work characteristics and employee outcomes in local government', International Journal of Human Resource Management, vol. 17, no. 10, pp. 1804-18.

Ohly, S., Sonnentag, S. \& Plunkte, F. 2006, 'Routinization, work characteristics and their relationships with creative and proactive behaviors', Journal of Organizational Behavior, vol. 27, no. 3, pp. 257-79.

Organ, D.W., Podsakoff, P.M. \& McKenzie, S.B. 2006, Organizational citizenship behavior: Its nature, antecedents and consequences, Sage Publications, Thousand Oaks.

Parker, S.K. \& Wall, T.D. 1998, Job and work design: Organizing work to promote well-being and effectiveness, Sage, San Francisco, California.

Parker, S.K., Wall, T.D. \& Cordery, J.L. 2001, 'Future work design research and practice: Towards an elaborated model of work design', Journal of Occupational and Organizational Psychology, vol. 74, no. 4, pp. 413-40.

Parker, S.K., Williams, H.M. \& Turner, N. 2006, 'Modeling the antecedents of proactive work behavior’, Journal of Applied Psychology, vol. 91, no. 3, pp. 636-52.

Peiperl, M. \& Jones, B. 2001, 'Workaholics or overworkers: Productivity or pathology?’, Group and Organization Management, vol. 26, no. 3, pp. 369-93.

Perry, J.L. \& Wise, L.R. 1990, 'The motivational bases of public service', Public Administration Review, vol. 50, no. 3, pp. 367-73.

Rainey, H. \& Steinbauer, P. 1999, 'Galloping elephants: Developing elements of a theory of effective government organizations', Journal of Public Administration Research and Theory, vol. 9, no. 1, pp. 1-32.

Randall, M.L., Cropanzano, R., Bormann, C.A. \& Birjulin, A. 1999, 'Organizational politics and organizational support as predictors of work attitudes, job performance, and organizational citizenship behavior’, Journal of Organizational Behavior, vol. 20, no. 2, pp. 159-74.

Rhoades, L. \& Eisenberger, R. 2002, 'Perceived organizational support: A review of the literature', Journal of Organizational Behavior, vol. 87, no. 4, pp. 698-714.

Shinn, S. 2004, 'The maverick CEO', BizEd, vol. 3, no. 2, pp. 16-21.

Skinner, S.J. 2000, 'Peak performance in the sales force', The Journal of Personal Selling and Sales Management, vol. 20, no. 1, pp. 37-42.

Smith, P., Kendall, L. \& Hulin, C. 1969, The Measurement of Satisfaction in Work and Retirement: A Strategy for the Study of Attitudes, Rand McNally, Chicago.

Spector, P.E. 1985, 'Measurement of human service staff satisfaction: Development of the job satisfaction survey', American Journal of Community Psychology, vol. 13, no. 5, pp. 693-713.

Spector, P.E. 1997, Job satisfaction: Application, assessment, causes, and consequences, Sage, Thousand Oaks, California. 
Stamper, C.L. \& Van Dyne, L. 2003, 'Organizational citizenship: A comparison between part-time and full-time service employees', Cornell Hotel and Restaurant Administration Quarterly, vol. 44, no. 1, pp. 33-42.

Steel, P. \& Konig, C.J. 2006, 'Integrating theories of motivation', Academy of Management Review, vol. 31, no. 4, pp. 889-913.

Steele, R.P. \& Ovalle, N.K. 1984, 'A review and meta-analysis of research on the relationship between behavioural intentions and employee turnover', Journal of Applied Psychology, vol. 69, no. 4, pp. 673-86.

Teo, S.T.T., Ahmad, T. \& Rodwell, J.J. 2003, 'HR role effectiveness and organizational culture in Australian local government', Asia Pacific Journal of Human Resources, vol. 41, no. 3, pp. 298315.

Tepper, B.J. 2000, ‘Consequences of abusive supervision’, Academy of Management Journal, vol. 43, no. 2, pp. 178-90.

Tepper, B.J., Duffy, M.K., Hoobler, J. \& Ensley, M.D. 2004, 'Moderators of the relationship between coworkers' organizational citizenship behavior and fellow employees' attitudes', Journal of Applied Psychology, vol. 89, no. 3, pp. 455-65.

Tett, R.P. \& Meyer, J.P. 1993, 'Job satisfaction, organizational commitment, turnover intention: Path analyses on meta-analytic findings’, Personnel Psychology, vol. 46, no. 2, pp. 259-93.

Tomer, J.F. 1981, 'Worker motivation: A neglected element in micro-micro theory', Journal of Economic Issues, vol. 15, no. 2, pp. 351-62.

Turnipseed, D. \& Murkison, G. 2000, 'Good soldiers and their syndrome: Organizational citizenship behavior and the work environment', North American Journal of Psychology, vol. 2, no. 2, pp. 281-303.

Uhl-Bien, M. \& Maslyn, J.M. 2003, 'Reciprocity in manager-subordinate relationships: Components, configurations, and outcomes', Journal of Management, vol. 29, no. 4, pp. 511-32.

Van Dyne, L., Graham, J.W. \& Dienesch, R.M. 1994, Organizational citizenship behavior: Construct redefinition, measurement, and validation. Academy of Management Journal, vol. 37, no. 4, pp. 765-802.

Vroom, V.H. 1964, Work and motivation, McGraw Hill, New York.

Williams, L.J. \& Anderson, S.E. 1991, 'Job satisfaction and organizational commitment as predictors of organizational citizenship and in-role behaviors', Journal of Management, vol. 17, no. 3, pp. 601-17.

Williams, K.D. \& Karau, S.J. 1991, 'Social loafing and social compensation: The effects of expectations of co-worker performance', Journal of Personality and Social Psychology, vol. 61, no. 4, pp. 570-81.

Worthington, A.C. \& Dollery, B.E. 2002, 'An analysis of recent trends in Australian local government', The International Journal of Public Sector Management, vol. 15, no. 6, pp. 496-515. 
Wright, B.E. 2001, 'Public-sector work motivation: A review of the current literature and a revised conceptual model', Journal of Public Administration Research and Theory, vol. 11, no. 4, pp. 55986.

Yankelovich, D. \& Immerwahr, J. 1983, Putting the work ethic to work, Public Agenda Foundation, New York. 


\section{Appendix}

Tab. 3. Correlations, means, standard deviations and scale reliabilities

\begin{tabular}{|c|c|c|c|c|c|c|c|c|c|c|c|c|c|c|c|c|c|c|}
\hline & Variables & 1 & 2 & 3 & 4 & 5 & 6 & 7 & 8 & 9 & 10 & 11 & 12 & 13 & 14 & 15 & 16 & 17 \\
\hline 1. & Job satisfaction & $(0.83)$ & & & & & & & & & & & & & & & & \\
\hline 2. & Intention to leave & $-0.64 \ddagger$ & $(0.92)$ & & & & & & & & & & & & & & & \\
\hline 3. & $\begin{array}{l}\text { DWE - Work } \\
\text { intensity }\end{array}$ & $0.34 \ddagger$ & $-0.33 \ddagger$ & $(0.83)$ & & & & & & & & & & & & & & \\
\hline 4. & DWE - Taking charge & $0.25 \ddagger$ & $-0.20 \ddagger$ & $0.36 \ddagger$ & $(0.87)$ & & & & & & & & & & & & & \\
\hline 5. & Challenging work & $0.66 \ddagger$ & $-0.48 \ddagger$ & $0.38 \ddagger$ & $0.33 \ddagger$ & $(0.89)$ & & & & & & & & & & & & \\
\hline 6. & $\begin{array}{l}\text { Team-oriented } \\
\text { leadership }\end{array}$ & $0.77 \ddagger$ & $-0.48 \ddagger$ & $0.29 \ddagger$ & $0.21 \ddagger$ & $0.61 \ddagger$ & $(0.94)$ & & & & & & & & & & & \\
\hline 7. & Co-worker support & $0.49 \ddagger$ & $-0.27 \ddagger$ & $0.32 \ddagger$ & $0.25 \ddagger$ & $0.37 \ddagger$ & $0.41 \ddagger$ & $(0.87)$ & & & & & & & & & & \\
\hline 8. & $\begin{array}{l}\text { Flexible work } \\
\text { arrangements }\end{array}$ & $0.48 \ddagger$ & $-0.32 \ddagger$ & $0.23 \ddagger$ & $0.27 \ddagger$ & $0.39 \ddagger$ & $0.40 \ddagger$ & $0.29 \ddagger$ & $(0.74)$ & & & & & & & & & \\
\hline 9. & $\begin{array}{l}\text { Recognition for good } \\
\text { performance }\end{array}$ & $0.66 \ddagger$ & $-0.50 \ddagger$ & $0.20 \ddagger$ & $0.19 \ddagger$ & $0.50 \ddagger$ & $0.57 \ddagger$ & $0.35 \ddagger$ & $0.54 \ddagger$ & $(0.82)$ & & & & & & & & \\
\hline 10. & $\begin{array}{l}\text { Autocratic leader } \\
\text { behaviour }\end{array}$ & $-0.64 \ddagger$ & $0.44 \ddagger$ & $-0.19 \dagger$ & $-0.13^{\dagger}$ & $-0.50 \ddagger$ & $-0.67 \ddagger$ & $-0.27 \ddagger$ & $-0.31 \ddagger$ & $-0.39 \ddagger$ & $(0.85)$ & & & & & & & \\
\hline 11. & Power-orientation & $-0.41 \ddagger$ & $0.37 \ddagger$ & $-0.20 \ddagger$ & 0.06 & $-0.31 \ddagger$ & $-0.38 \ddagger$ & $-0.21 \ddagger$ & $-0.21 \ddagger$ & $-0.46 \ddagger$ & $0.34 \ddagger$ & $(0.79)$ & & & & & & \\
\hline 12. & Co-worker shirking & $-0.41 \ddagger$ & $0.27 \ddagger$ & $-0.15^{\dagger}$ & $-0.11 \bar{\uparrow}$ & $-0.26 \ddagger$ & $-0.30 \ddagger$ & $-0.58 \ddagger$ & $-0.17 \ddagger$ & $-0.27 \ddagger$ & $0.30 \ddagger$ & $0.33 \ddagger$ & $(0.90)$ & & & & & \\
\hline 13. & Monetary reward $^{\mathrm{a}}$ & $0.13+$ & -0.04 & 0.02 & $0.20 \ddagger$ & $0.19 \ddagger$ & 0.05 & 0.05 & $0.17 \ddagger$ & $0.13 \dagger$ & -0.07 & 0.02 & $-0.14 \dagger$ & - & & & & \\
\hline 14. & Gender $^{b}$ & $0.16 \ddagger$ & $-0.14 \dagger$ & $0.23 \ddagger$ & 0.05 & $0.12 *$ & $0.10 \bar{\uparrow}$ & $0.10 \bar{\uparrow}$ & $0.12 *$ & $0.10 \bar{\uparrow}$ & $-0.14 \dagger$ & -0.01 & $-0.11 \bar{\uparrow}$ & $-0.20 \ddagger$ & - & & & \\
\hline 15. & $\mathrm{Age}^{\mathrm{a}}$ & 0.05 & -0.08 & $0.14 t^{+}$ & $0.11 \bar{\uparrow}$ & 0.07 & -0.07 & 0.05 & -0.04 & 0.03 & 0.04 & $-0.09 \bar{\uparrow}$ & -0.07 & $0.13^{*}$ & -0.081 & - & & \\
\hline 16. & Work status $^{c}$ & $-0.13+$ & $0.18 \ddagger$ & $-0.14 \dagger$ & 0.06 & -0.03 & $-0.10 \bar{\uparrow}$ & $-0.11 \bar{\uparrow}$ & $-0.10 \bar{\uparrow}$ & -0.09 & 0.06 & $0.17 \ddagger$ & 0.07 & $0.41 \neq$ & $-0.31 \ddagger$ & -0.06 & - & \\
\hline \multirow[t]{3}{*}{17.} & $\begin{array}{l}\text { Organisational } \\
\text { tenure }^{\mathrm{a}}\end{array}$ & -0.07 & 0.05 & -0.02 & 0.02 & -0.03 & $-0.11 \dagger$ & -0.06 & $-0.12^{*}$ & $-0.16 \ddagger$ & $0.09 \bar{\uparrow}$ & 0.07 & 0.04 & 0.06 & -0.09 & $0.42 \ddagger$ & $0.11 \bar{\uparrow}$ & - \\
\hline & MEAN & 5.18 & 3.52 & 5.95 & 5.58 & 5.33 & 5.27 & 5.46 & 4.81 & 4.69 & 2.50 & 4.20 & 2.72 & 3.03 & 0.40 & 0.84 & 3.80 & 1.67 \\
\hline & S.D. & 1.22 & 1.97 & 0.88 & 0.89 & 1.27 & 1.43 & 1.11 & 1.31 & 1.27 & 1.41 & 1.39 & 1.37 & 1.70 & 0.49 & 0.37 & 1.09 & 0.98 \\
\hline
\end{tabular}

Significance test criteria: $\bar{\uparrow} \mathrm{p}<0.05 ; * \mathrm{p}<0.01 ; \dagger \mathrm{p}<0.005 ; \ddagger \mathrm{p}<0.001$

Pearson correlations on the lower diagonal; Cronbach's alpha reliabilities in parentheses along the diagonal.

${ }^{a}$ Variable correlations approximate - variable measures treated as interval scales. ${ }^{b}$ Coded as $0=$ male and $1=$ female. ${ }^{\mathrm{c}}$ Coded as $0=$ part-time/casual and $1=$ full-time. 
Tab. 4. Pairwise regression results

\begin{tabular}{|c|c|c|c|c|c|c|c|c|c|c|}
\hline & \multicolumn{10}{|c|}{ Predictor variables - work outcomes } \\
\hline & \multicolumn{5}{|c|}{ Job satisfaction } & \multicolumn{5}{|c|}{ Intention to leave } \\
\hline & $\Delta \mathrm{R}^{2}$ & $\Delta \mathrm{F}$ & $\beta_{u}{ }^{a}$ & $\beta_{s}{ }^{a}$ & $\mathrm{ESr}^{\mathrm{b}}$ & $\Delta \mathrm{R}^{2}$ & $\Delta \mathrm{F}$ & $\beta_{u}{ }^{a}$ & $\beta_{s}{ }^{a}$ & $\mathrm{ESr}^{\mathrm{b}}$ \\
\hline Step 1. Control Variables & 0.046 & $5.94 \ddagger$ & & & & 0.053 & $8.67 \ddagger$ & & & \\
\hline Gender & & & $0.33+$ & $0.13+$ & $0.16^{x}$ & & & $-0.40 \bar{\uparrow}$ & $-0.10 \bar{\uparrow}$ & $-0.14^{x}$ \\
\hline Age & & & 0.09 & 0.08 & 0.05 & & & $-0.18 \bar{\uparrow}$ & $-0.10 \bar{\uparrow}$ & -0.08 \\
\hline Work status & & & $-0.33 \bar{\uparrow}$ & $-0.10 \bar{\uparrow}$ & $-0.13^{x}$ & & & $0.80+$ & $0.15^{\dagger}$ & $0.18^{x}$ \\
\hline Organisational tenure & & & -0.09 & -0.07 & -0.07 & & & 0.11 & 0.05 & 0.05 \\
\hline \multicolumn{11}{|l|}{ Step 2. Pairwise predictor variables } \\
\hline Model 1 Challenging work & 0.41 & $369.52 \ddagger$ & $0.63 \ddagger$ & $0.65 \ddagger$ & $0.66^{2}$ & 0.21 & $136.52 \ddagger$ & $-0.73 \ddagger$ & $-0.46 \ddagger$ & $-0.48^{2}$ \\
\hline Model 2 Team-oriented leadership & 0.57 & $710.78 \ddagger$ & $0.65 \ddagger$ & $0.76 \ddagger$ & $0.77^{2}$ & 0.21 & $135.56 \ddagger$ & $-0.64 \ddagger$ & $-0.46 \ddagger$ & $-0.48^{2}$ \\
\hline Model 3 Co-worker support & 0.20 & $125.18 \ddagger$ & $0.50 \ddagger$ & $0.45 \ddagger$ & $0.49^{2}$ & 0.05 & $26.35 \ddagger$ & $-0.41 \ddagger$ & $-0.23 \ddagger$ & $-0.27^{y}$ \\
\hline Model 4 Flexible work arrangements & 0.20 & $131.48 \ddagger$ & $0.42 \ddagger$ & $0.46 \ddagger$ & $0.48^{2}$ & 0.08 & $47.17 \ddagger$ & $-0.44 \ddagger$ & $-0.30 \ddagger$ & $-0.32^{y}$ \\
\hline Model 5 Recognition for good performance & 0.40 & $354.86 \ddagger$ & $0.62 \ddagger$ & $0.65 \ddagger$ & $0.66^{2}$ & 0.22 & $146.37 \ddagger$ & $-0.74 \ddagger$ & $-0.48 \ddagger$ & $-0.50^{2}$ \\
\hline Model 6 Autocratic leader behaviour & 0.38 & $318.18 \ddagger$ & $-0.54 \ddagger$ & $-0.62 \ddagger$ & $-0.64^{2}$ & 0.17 & $108.05 \ddagger$ & $0.59 \ddagger$ & $0.42 \ddagger$ & $0.44^{2}$ \\
\hline Model $7 \quad$ Power-orientation & 0.15 & $94.02 \ddagger$ & $-0.35 \ddagger$ & $-0.40 \ddagger$ & $-0.41^{2}$ & 0.11 & $63.41 \ddagger$ & $0.48 \ddagger$ & $0.34 \ddagger$ & $0.37^{y}$ \\
\hline Model 8 Co-worker shirking & 0.15 & $90.32 \ddagger$ & $-0.34 \ddagger$ & $-0.39 \ddagger$ & $-0.41^{2}$ & 0.05 & $28.94 \ddagger$ & $0.34 \ddagger$ & $0.23 \ddagger$ & $0.27^{y}$ \\
\hline Monetary reward (interval scale) & 0.05 & $24.33 \ddagger$ & $0.17 \ddagger$ & $0.24 \ddagger$ & $0.13^{x}$ & 0.00 & 0.47 & -0.04 & -0.03 & -0.04 \\
\hline Monetary reward (categorical measure) & 0.07 & $4.26 \ddagger$ & & & & 0.02 & 0.83 & & & \\
\hline Model 10 Job satisfaction & & & & & & 0.37 & $317.46 \ddagger$ & $-1.025 \ddagger$ & $-0.63 \ddagger$ & $-0.64^{2}$ \\
\hline Model 11 Turnover intentions & & & & & & & & & & \\
\hline
\end{tabular}

$\bar{\uparrow} \mathrm{p}<0.05 ; * \mathrm{p}<0.01 ; \dagger \mathrm{p}<0.005 ; \neq \mathrm{p}<0.001(\mathrm{n}=500)$

${ }^{a}$ Control variables beta coefficients are for the Step 1 regression; $\beta_{\mathrm{u}}=$ unstandardised beta coefficient; $\beta_{\mathrm{s}}=$ standardised beta coefficient;

${ }^{\mathrm{b}} \mathrm{ES}_{\mathrm{r}}=$ Effect size correlation using cut-off criteria: ${ }^{\mathrm{x}}$ small $(\mathrm{r}>0.100) ;{ }^{\mathrm{y}}$ medium $(\mathrm{r}>0.243) ;{ }^{\mathrm{z}}$ large $(\mathrm{r}>0.371)$

Gender -0 = male and 1 = female; Work status $-0=$ full-time and 1 = part-time/casual; Monetary reward (categorical) - under $\$ 30,000$ reference group. 
Tab. 4 cont. Pairwise regression results

\begin{tabular}{|c|c|c|c|c|c|c|c|c|c|c|}
\hline & \multicolumn{10}{|c|}{ Predictor variables - work outcomes } \\
\hline & \multicolumn{5}{|c|}{ DWE - work intensity } & \multicolumn{5}{|c|}{ DWE - Taking charge } \\
\hline & $\Delta \mathrm{R}^{2}$ & $\Delta \mathrm{F}$ & $\beta_{u}{ }^{a}$ & $\beta_{s}{ }^{a}$ & $\mathrm{ESr}^{\mathrm{b}}$ & $\Delta \mathrm{R}^{2}$ & $\Delta \mathrm{F}$ & $\beta_{u}{ }^{a}$ & $\beta_{s}{ }^{a}$ & $\mathrm{ESr}^{\mathrm{b}}$ \\
\hline Step 1. Control Variables & 0.09 & $11.42 \ddagger$ & & & & 0.023 & $2.87 \bar{\uparrow}$ & & & \\
\hline Gender & & & $0.41 \ddagger$ & $0.23 \ddagger$ & $0.23^{x}$ & & & 0.17 & 0.09 & 0.05 \\
\hline Age & & & $0.14 \ddagger$ & $0.17 \ddagger$ & $0.14^{x}$ & & & $0.10 \bar{\uparrow}$ & $0.12 \bar{\uparrow}$ & $0.11^{x}$ \\
\hline Work Status & & & -0.14 & -0.06 & $-0.14^{x}$ & & & 0.22 & 0.09 & 0.06 \\
\hline Organisational tenure & & & -0.05 & -0.05 & -0.02 & & & 0.01 & 0.01 & 0.02 \\
\hline \multicolumn{11}{|l|}{ Step 2. Pairwise predictor variables } \\
\hline Model 1 Challenging Work & 0.13 & $78.61 \ddagger$ & $0.26 \ddagger$ & $0.36 \ddagger$ & $0.38^{2}$ & 0.10 & $56.64 \ddagger$ & $0.23 \ddagger$ & $0.32 \ddagger$ & $0.33^{y}$ \\
\hline Model 2 Team-oriented Leadership & 0.07 & $41.41 \ddagger$ & $0.17 \ddagger$ & $0.27 \ddagger$ & $0.29^{y}$ & 0.05 & $24.29 \ddagger$ & $0.14 \ddagger$ & $0.22 \ddagger$ & $0.21^{x}$ \\
\hline Model $3 \quad$ Co-worker support & 0.08 & $46.52 \ddagger$ & $0.24 \ddagger$ & $0.29 \ddagger$ & $0.32^{y}$ & 0.06 & $33.75 \ddagger$ & $0.21 \ddagger$ & $0.26 \ddagger$ & $0.25^{y}$ \\
\hline Model $4 \quad$ Flexible Work Arrangements & 0.04 & $21.88 \ddagger$ & $0.14 \ddagger$ & $0.20 \ddagger$ & $0.23^{x}$ & 0.08 & $43.54 \ddagger$ & $0.20 \ddagger$ & $0.29 \ddagger$ & $0.27^{y}$ \\
\hline Model 5 Recognition for Good Performance & 0.03 & $13.75 \ddagger$ & $0.11 \ddagger$ & $0.16 \ddagger$ & $0.20^{x}$ & 0.03 & $17.53 \ddagger$ & $0.13 \ddagger$ & $0.19 \ddagger$ & $0.19^{\mathrm{x}}$ \\
\hline Model 6 Autocratic Leader Behaviour & 0.03 & $13.92 \ddagger$ & $-0.10 \ddagger$ & $-0.16 \ddagger$ & $-0.19^{x}$ & 0.02 & $7.97^{*}$ & $-0.08^{*}$ & $-0.13^{*}$ & $-0.13^{x}$ \\
\hline Model 7 Power-orientation & 0.03 & $17.71 \ddagger$ & $-0.12 \ddagger$ & $-0.18 \ddagger$ & $-0.20^{x}$ & 0.00 & 1.68 & -0.04 & 0.06 & -0.06 \\
\hline Model $8 \quad$ Co-worker shirking & 0.01 & $6.27 \bar{\uparrow}$ & $-0.07 \bar{\uparrow}$ & $-0.11 \bar{\uparrow}$ & $-0.15^{x}$ & 0.01 & $4.77 \bar{\uparrow}$ & $-0.06 \bar{\uparrow}$ & $-0.10 \bar{\uparrow}$ & $-0.11^{x}$ \\
\hline Monetary reward (interval scale) & 0.00 & 0.54 & 0.02 & 0.04 & 0.02 & 0.03 & $17.12 \ddagger$ & $0.11 \ddagger$ & $0.20 \ddagger$ & $0.20^{x}$ \\
\hline Monetary reward (categorical measure) & 0.01 & 0.85 & - & - & - & 0.06 & $3.44 \ddagger$ & - & - & - \\
\hline Model 10 Job satisfaction & 0.08 & $49.02 \ddagger$ & $0.22 \ddagger$ & $0.30 \ddagger$ & $0.34^{y}$ & 0.06 & $31.56 \ddagger$ & $0.19 \ddagger$ & $0.25 \ddagger$ & $0.25^{y}$ \\
\hline Model 11 Turnover intentions & 0.08 & $44.71 \ddagger$ & $-0.13 \ddagger$ & $-0.29 \ddagger$ & $-0.33^{y}$ & 0.04 & $18.90 \ddagger$ & $-0.09 \ddagger$ & $-0.20 \ddagger$ & $-0.20^{x}$ \\
\hline
\end{tabular}

$\overline{\mathrm{T}}_{\mathrm{p}}<0.05 ;{ }^{*} \mathrm{p}<0.01$; $\uparrow \mathrm{p}<0.005 ; \ddagger \mathrm{p}<0.001(\mathrm{n}=500)$

${ }^{a}$ Control variables beta coefficients are for the Step 1 regression; $\beta_{\mathrm{u}}=$ unstandardised beta coefficient; $\beta_{\mathrm{s}}=$ standardised beta coefficient;

$\mathrm{ES}_{\mathrm{r}}=$ Effect size correlation using cut-off criteria: ${ }^{\mathrm{x}}$ small $(\mathrm{r}>0.100) ;{ }^{\mathrm{y}}$ medium $(\mathrm{r}>0.243) ;{ }^{\mathrm{z}}$ large $(\mathrm{r}>0.371)$

Gender $-0=$ male and $1=$ female; Work status $-0=$ full-time and $1=$ part-time/casual; Monetary reward (categorical) - under $\$ 30,000$ reference group. 
Tab. 5. Multiple regression results (excluding uncorrelated predictor variables)

\begin{tabular}{|c|c|c|c|c|c|c|c|c|c|c|c|c|}
\hline \multirow[b]{2}{*}{ Step 1: } & \multicolumn{3}{|c|}{ Job satisfaction } & \multicolumn{3}{|c|}{ Turnover intentions } & \multicolumn{3}{|c|}{ Discretionary work intensity } & \multicolumn{3}{|c|}{$\begin{array}{c}\text { Discretionary directed effort - } \\
\text { taking charge }\end{array}$} \\
\hline & $\beta_{\mathrm{u}}$ & SE & $\beta_{s}$ & $\beta_{u}$ & SE & $\beta_{\mathrm{s}}{ }^{\mathrm{a}}$ & $\beta_{\mathrm{u}}$ & SE & $\beta_{s}{ }^{a}$ & $\beta_{u}$ & SE & $\beta_{\mathrm{s}}{ }^{\mathrm{a}}$ \\
\hline Constant & 5.32 & 0.29 & & 3.29 & 0.47 & & 5.54 & 0.21 & & 4.94 & 0.21 & \\
\hline Gender & 0.33 & 0.12 & $0.13+$ & -0.40 & 0.19 & $-0.10 \bar{\uparrow}$ & 0.41 & 0.08 & $0.23 \ddagger$ & 0.17 & 0.09 & 0.09 \\
\hline Age & 0.09 & 0.05 & 0.08 & -0.18 & 0.09 & $-0.10 \bar{\uparrow}$ & 0.14 & 0.04 & $0.17 \ddagger$ & 0.10 & 0.04 & $0.12 \bar{\uparrow}$ \\
\hline Work Status & -0.33 & 0.16 & $-0.10 \bar{\uparrow}$ & 0.80 & 0.26 & $0.15^{\dagger}$ & -0.14 & 0.11 & -0.06 & 0.22 & 0.12 & 0.09 \\
\hline Organisational Tenure & -0.09 & 0.06 & -0.07 & 0.11 & 0.10 & -0.05 & 0.05 & 0.04 & -0.05 & 0.01 & 0.05 & 0.01 \\
\hline \multicolumn{13}{|l|}{ Step 2: } \\
\hline Constant & 1.33 & 0.34 & & 6.00 & 0.88 & & 3.25 & 0.43 & & 2.36 & 0.44 & \\
\hline Gender & 0.08 & 0.06 & 0.03 & -0.12 & 0.16 & -0.03 & 0.35 & 0.08 & $0.19 \ddagger$ & 0.11 & 0.08 & 0.06 \\
\hline Age & 0.03 & 0.03 & 0.03 & -0.09 & 0.07 & -0.05 & 0.11 & 0.04 & $0.14 \dagger$ & 0.06 & 0.04 & 0.07 \\
\hline Work status & -0.16 & 0.09 & -0.05 & 0.59 & 0.21 & $0.11 *$ & 0.01 & 0.10 & 0.00 & 0.20 & 0.12 & 0.08 \\
\hline Organisational tenure & 0.05 & 0.03 & 0.04 & -0.04 & 0.08 & -0.02 & -0.03 & 0.04 & -0.03 & 0.04 & 0.04 & 0.05 \\
\hline Challenging work & 0.17 & 0.03 & $0.18 \ddagger$ & -0.32 & 0.08 & $-0.20 \ddagger$ & 0.21 & 0.04 & $0.29 \ddagger$ & 0.17 & 0.04 & $0.23 \ddagger$ \\
\hline Team-oriented leadership & 0.29 & 0.03 & $0.34 \ddagger$ & -0.10 & 0.08 & -0.07 & 0.06 & 0.04 & 0.10 & 0.02 & 0.04 & 0.04 \\
\hline Co-worker support & 0.09 & 0.03 & $0.08^{*}$ & 0.06 & 0.09 & 0.03 & 0.20 & 0.04 & $0.24 \ddagger$ & 0.16 & 0.05 & $0.20 \ddagger$ \\
\hline Flexible work arrangements & 0.05 & 0.03 & 0.05 & -0.01 & 0.07 & -0.01 & 0.06 & 0.03 & 0.09 & 0.12 & 0.04 & $0.18 \ddagger$ \\
\hline Recognition for good performance & 0.21 & 0.03 & $0.22 \ddagger$ & -0.38 & 0.08 & $-0.24 \ddagger$ & -0.11 & 0.04 & $-0.16 t^{\alpha}$ & -0.05 & 0.04 & -0.08 \\
\hline Autocratic leader behaviour & -0.14 & 0.03 & $-0.17 \ddagger$ & 0.22 & 0.07 & $0.16+$ & 0.05 & 0.03 & 0.08 & 0.04 & 0.04 & 0.07 \\
\hline Co-worker shirking & -0.08 & 0.03 & $-0.09+$ & 0.09 & 0.07 & 0.06 & 0.07 & 0.03 & $0.11 \bar{\uparrow}^{\alpha}$ & 0.05 & 0.03 & 0.08 \\
\hline Power-orientation & -0.01 & 0.02 & -0.01 & 0.11 & 0.06 & 0.07 & -0.08 & 0.03 & $-0.13^{*}$ & & & \\
\hline Monetary reward (interval scale) & 0.03 & 0.02 & 0.04 & & & & & & & $0.06 \bar{\uparrow}$ & 0.03 & $0.11 \bar{\uparrow}$ \\
\hline Initial Model $\mathbf{R}^{2}$ & & 0.05 & & & 0.05 & & & 0.09 & & & 0.02 & \\
\hline$\Delta R^{2}$ for Step 2 & & 0.71 & & & 0.33 & & & 0.19 & & & 0.17 & \\
\hline
\end{tabular}

$\bar{\uparrow} p<0.05 ; * p<0.01 ; \dagger p<0.005 ; \ddagger p<0.001$ ( $n=500) ; \beta_{u}=$ unstandardised beta coefficient; $\beta_{\mathrm{s}}=$ standardised beta coefficient; SE = standard error of b-coefficient

${ }^{\alpha}$ Unexpected reversal of sign in the multiple regression - possible confounding effect. 